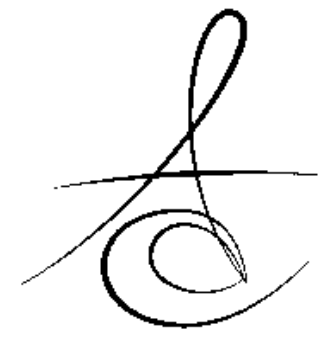

\section{VERTİKAL KÖK KIRIĞI OLAN MANDİBULAR MOLAR DİŞİN HEMİSEKSİYON YÖNTEMİ İLE TEDAVİSİ: OLGU SUNUMU}

\section{VERTICAL ROOT FRACTURE OF THE MANDIBULAR MOLAR TOOTH WITH HEMISECTION TREATMENT METHOD: A CASE REPORT}

\author{
Dr. İbrahim UYSAL ${ }^{*}$ \\ Prof. Dr. Remzi NİĞİz**
}

\author{
Doç. Dr. Sadullah KAYA* \\ Arş. Gör. Rojdan Ferman GÜNEŞ ${ }^{* * *}$
}

Makale Kodu/Article code: 2039

Makale Gönderilme tarihi: 17.12.2014

Kabul Tarihi: 07.04.2015

\section{ÖZET}

Aşırı kron harabiyeti, periodontal hastalığı ve kök kırığı bulunan çok köklü bir dişin hemiseksiyon yöntemi ile ağız içinde tutulması mümkündür. Bu çalışmada, meziyal kökünde vertikal kök kırığı bulunan sağ alt ikinci molar dişin distal kanalında kanal tedavisi yenilendi. Vertikal kök kırığına sahip mesial kök, distal kökten ayrılarak hemiseksiyon yöntemiyle uzaklaştırıldı. Bir sonraki seans distal kök fiber post uygulanarak restore edildi ve mesial köke ait çekim kavitesinin iyileşmesinin ardından sağ birinci mandibular molar ve sağ ikinci mandibular molar dişlere metal destekli porselen köprü protezi uygulanmasıyla tedavi tamamlandı. Üç yıl sonra gerçekleştirilen kontrol seansında, dişin klinik ve radyografik olarak sağlıklı olduğu görüldü. Hemiseksiyon tekniği, dental oklüzyonun devamIılı̆ının sağlanması, tedavi işlemlerinin kısa sürmesi ve tedavi maliyetinin düşük olması gibi nedenlerle günümüzde tercih edilen bir tedavi yöntemidir.

Anahtar Kelimeler: Hemiseksiyon, vertikal kök kırığı, fiber post

\section{GİRIŞ}

Vertikal kök kırığı, apikal uçtan başlayıp koronere doğru uzunlamasına ilerleyen bir kırık tipi olarak adlandırımaktadır ${ }^{1}$. Kök kanallarının fazla genişletilmesi, lateral-vertikal kompaksiyon sırasında ve post uygulanması sırasında aşırı kuvvet uygulanması, geniş post yuvası oluşturulması ve aşırı kron harabiyeti nedeniyle diş bütünlüğündeki bozulmalar vertikal kök kırığını oluşturan risk faktörleri olarak sıralanabilir ${ }^{2}$.

\begin{abstract}
Retaining the teeth is possible with hemisection teqnique by many reasons such as extreme crown destruction, periodontal troubles and root fracture. In this study, distal canal endodontic treatment of right second molar tooth which has vertical fracture on mesial root has been renewed. Fractured mesial root has been removed from distal root by hemisection technique. In the next appointment, fiber post-core restoration has been generated and after healing extraction cavity caused by being removed of mesial root, has been completed with the porcelain-fused-tometal bridge to the mandibular right first molar and mandibular right second molar teeth. After tree year follow-up, it's observed that the teeth are healty clinically and radiographically. Hemisection teqnique may be prefered because of some reasons such as having progression of dental occlusion, short treatment process and the low treatment cost.
\end{abstract}

Key Words: Hemisection, vertical root fracture, fiber post

Hemiseksiyon; mandibular molar dişlerde uygulanan, dişin kökünün ve ilgili kuron parçasının furkasyon hattı boyunca ikiye ayrılarak, zarar görmüş kısmın çıkarılıp sağlam kalan bölümünün yerinde bırakılarak korunması işlemidir ${ }^{3}$. Çok köklü dişin bir kökünü içeren ilerlemiş periodontitis vakaları, komplike kron-kök kırıkları, kanalda kırık alet bulunması ve strip kök perforasyonları gibi iyatrojenik komplikasyonlar, alveolar kemiğe kadar uzanan derin çürükler hemiseksiyon yönteminin endikasyonları arasında bulunmaktadır ${ }^{4}$.

*Dicle Üniversitesi Diş Hekimliği Fakültesi Endodonti A.D.

**Dicle Üniversitesi Diş Hekimliği Fakültesi Protetik Diş Tedavisi A. D.

***Dicle Üniversitesi Diş Hekimliği Fakültesi Ağız, Diş ve Çene Hastalıkları ve Cerrahisi A. D. 
Atatürk Üniv. Diş Hek. Fak. Derg.

] Dent Fac Atatürk Uni

Supplement: 13, Yıl: 2015, Sayfa : 32-36

Bu çalışmada, vertikal-kök kırığı bulunan mandibular ikinci molar dişin hemiseksiyon yöntemiyle tedavisi ve üç yıllık takibi anlatılmıştır.

\section{OLGU SUNUMU}

Altmış iki yaşında bayan hasta, önceden kanal tedavisi uygulanmış ve kuron ile restore edilmiş bir dişinin üç gün önce çiğneme sırasında kırıldığını bildirerek, ağrı şikayetiyle endodonti kliniğimize başvurdu.

Klinik muayenede hastanın sağ alt ikinci büyük azı dişinde kron harabiyeti olduğu gözlenirken radyografik incelemede dişin kanal tedavili olduğu ve meziyal kökünde vertikal kök kırığı varlığı tespit edildi (Resim 1). Yapılan endodontik ve protetik değerlendirmeler sonucunda distal kökte herhangi bir patoloji görülmediğinden hemiseksiyon yöntemiyle ağızda tutulmasına karar verildi.

Distal kökteki kanal dolgusu, ProTaper (DentsplyMaillefer, Ballaigues, Switzerland) kanal yenileme eğeleri D1 ve D2 kullanılarak uzaklaştırıldı. Distal kök klinik açıdan semptomsuz olduğu için aynı seansta ProTaper (DentsplyMaillefer, Ballaigues, Switzerland) döner eğe sistemi kullanılarak, \% 2,5'lik $\mathrm{NaOCl}$ ve \% 17 'lik EDTA kanal irrigasyonu altında F3 numaralı döner eğeye kadar yeniden şekillendirildi, yıkama ve kurutma işlemlerinin ardından kök kanalı $\mathrm{AH}$ 26 (Dentsply, Konstanz, Germany) kanal dolgu patı ve gütaperka ile hermetik bir şekilde dolduruldu (Resim 2). Kanal ağzı cam iyonomer kaide simanı (VOCO, Germany) kullanılarak kapatıldı. Tedavinin tek seansta yapılmasının nedeni hem semptomsuz olması hem de kronal seviye dişeti hizasında olduğu için çekim sonrası oluşabilecek koronal sızdırmanın önüne geçebilmekti. Endodontik tedavinin tamamlanmasını takiben lokal anastezi altında distal kök ile meziyal kök, elmas frezlerle distile su soğutması altında bifurkasyon bölgesi boyunca kesilerek birbirlerinden ayrılıp meziyal kök alveolünden uzaklaştırıldı (Resim 3). Sonraki seansta dişin protetik olarak restore edilebilmesi için kanal dolgusunun koronal 2/3'lük kısmı fiber post sisteminin freziyle kanaldan uzaklaştırıldı ve fiber post (Snowpost, Abrasivetechnology, ABD) dual cure adheziv simanla (Panavia $F \quad 2,0$ ve Clearfil SA, KurarayCo, Osaka, Japan) distal kök kanalına simante edildi ve rezin modifiye cam iyonomer simanla (GC FujiVII CAPSULE, GC Corporation, Japan) post-core
UYSAL, KAYA, NİĞİZ,

GÜNEŞ

restorasyonu oluşturuldu (Resim 4).

Çekim boşluğunun kapanmasının ardından kole adaptasyonu kaybolmuş olan sağ birinci büyük azı dişinin kuronu sökülerek (Resim 5). Diş kompozit rezin ile restore edildi. Sağ birinci mandibular molar diş ile sağ ikinci mandibular molar dişin distal kökü dayanak alınarak köprü protezi planlaması yapıldı (Resim 6). Gerekli proteteik hazırılar yapıldıktan sonra silikon ölçü maddesi (Elite HD+, Zhermack, Rovigo, Italy) yardımıyla tüm ağız ölçüleri alındı. Metal ve dentin prova işlemleri sonrası metal destekli porselen köprü protezinin cam iyonomer simanla daimi simantasyonu yapılarak tedavi tamamlandı.

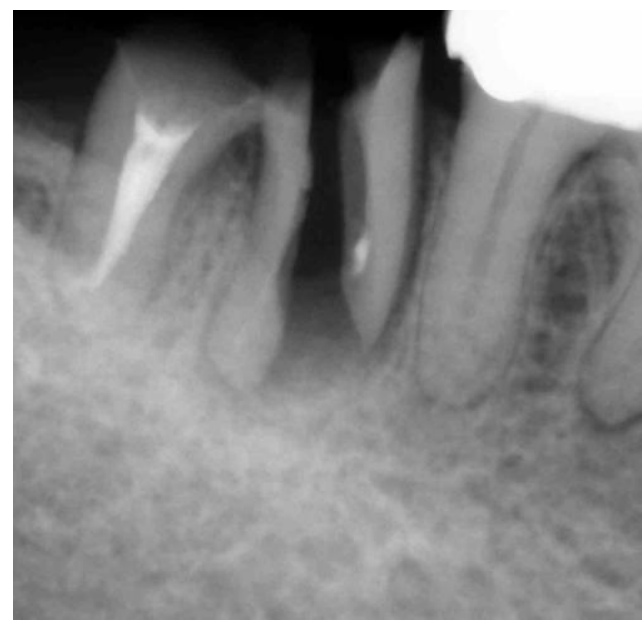

Resim 1. Tedavi öncesi teşhis radyografisi.

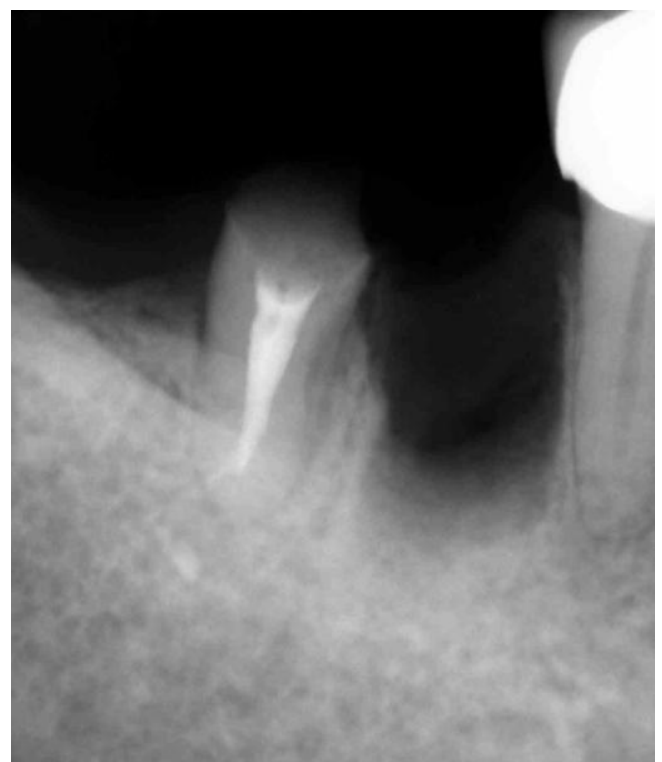

Resim 2. Kanal dolgu yenilenmesi sonrası distal kökün radyografisi. 
Atatürk Üniv. Diş Hek. Fak. Derg.

J Dent Fac Atatürk Uni

Supplement: 13, Yll: 2015, Sayfa : 32-36

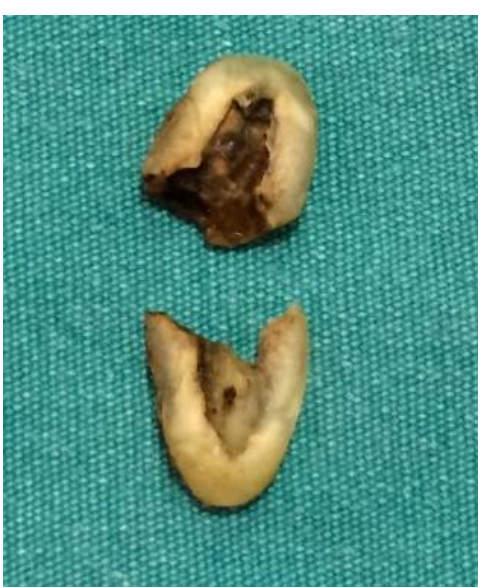

Resim 3. Vertikal kök kırığı bulunan mesial kökün görünümü.

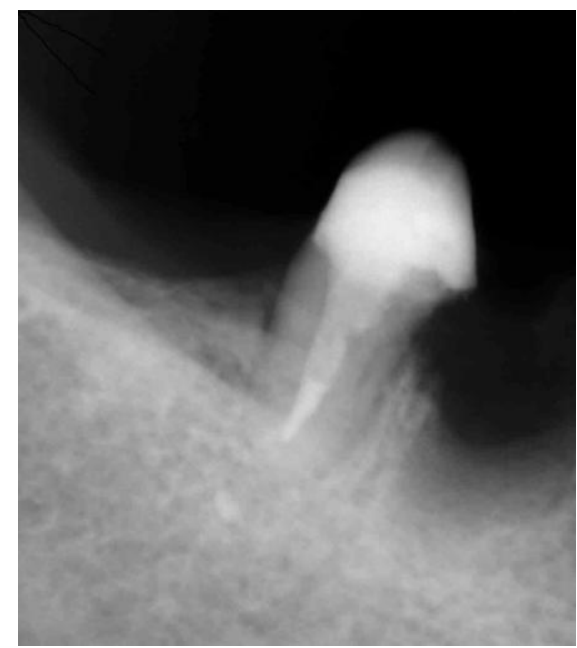

Resim 4. Fiber post simantasyonu sonrası oluşturulan postcore restorasyonu.

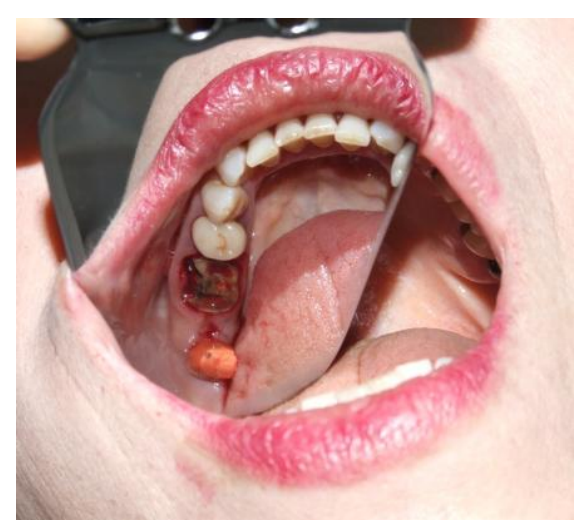

Resim 5. Sağ birinci mandibular molar dişin kuron sökümü sonrası ağız içi görünümü.
UYSAL, KAYA, NİĞİZ, GÜNEŞ

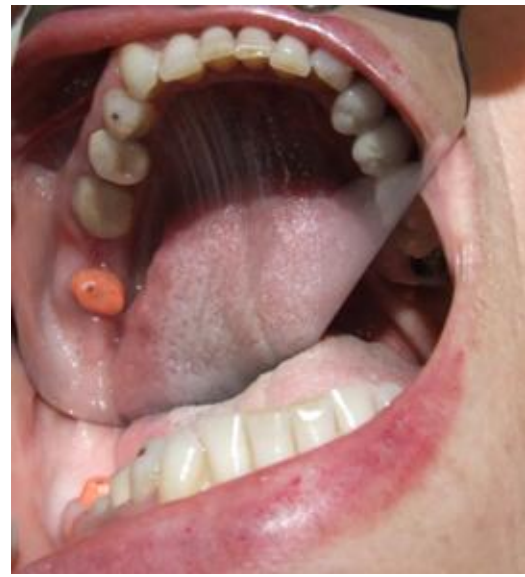

Resim 6. Sağ ikinci mandibular molar dişin komposit restorasyon sonrası ağız içi görünümü.

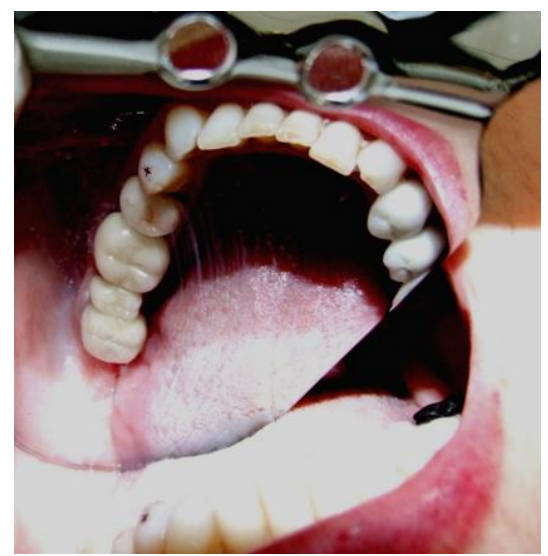

Resim 7. Üç yıl sonraki kontrol seansında köprü protezinin ağız içi görünümü.

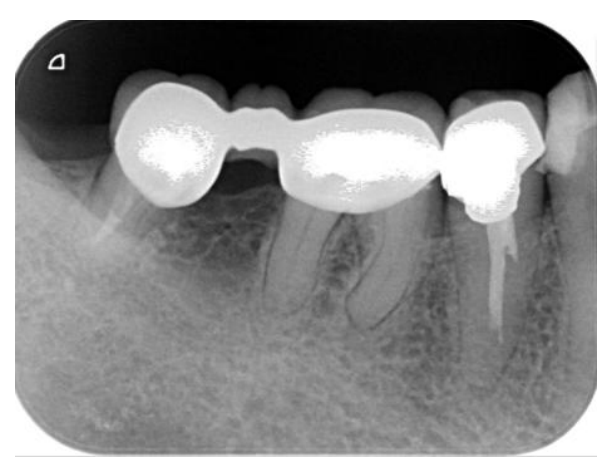

Resim 8. Tedaviden üç yıl sonra alınan periapikal radyografik görünüm.

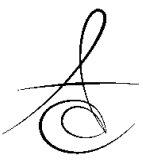


Atatürk Üniv. Diş Hek. Fak. Derg.

J Dent Fac Atatürk Uni

Supplement: 13, Yıl: 2015, Sayfa : 32-36
UYSAL, KAYA, NİĞİZ,

GÜNEŞ

\section{TARTIŞMA}

Vertikal kök kırığı periodontal ligament ve yumuşak doku hasarının yanısıra kırık parçaların sebep olduğu alveol kemik rezorbsiyonlarına da yol açmaktadır ${ }^{5}$. Bu vakalarda oral dokuların korunması ve hasta konforunun sağlanması açısından hızlı teşhis ve tedavinin uygulanması gerekmektedir.

Vertikal kök kırıklarının teşhisinde; konvansiyonel radyografiler ve bilgisayarlı tomografi gibi görüntüleme tekniklerinden, x-ray, periodontal sondlama, boyama, cerrahi inceleme, ısırma testi, kırı̆ın direkt olarak gözlemlenmesi, operasyon mikroskobu ile incelemesi gibi yöntemlerden faydalanılmaktadır 6,7. Mevcut vakada, kırık hattının direkt olarak gözlemlenebilmesi ve $\mathrm{x}$-ray incelemesiyle de doğrulanabilmesi açısından daha ileri diagnostik tekniklerin kullanılmasına gerek kalmamıştır.

Vertikal kök kırığı bulunan dişlerin prognozunun kötü olması nedeniyle genellikle çekim endikasyonu konulmaktadır. Bazı araştırmacılar farklı tedavi yöntemleri uygulayarak dişin ağızda tutulmasını sağlamışlardır. Özer ve arkadaşları ${ }^{8}$ yaptıkları bir çalışmada vertikal kök kırığı bulunan anterior üst premolar dişin cerrahi çekimi sonrası kırık parçalarını adheviz simanla yapıştırdıktan sonra dişi reimplante ederek oklüzyonun devamlılığını tekrar sağlamışlardır. Benzer yöntemler kullanılarak vertikal kök kırığı tedavileri literatürlerde mevcuttur ${ }^{9-12}$.

Floratos ve Kratchman ${ }^{13}$ maksiller ve mandibular molar dişlerde tamamlanmamış vertikal kök kırığı bulunan dişlerin cerrahi rezeksiyonla tedavilerini içeren dört vakayı sunmuşlardır. Bu çalışmada kırık hattı apikal bölgeyle sınırlı kaldığı için apikal kök rezeksiyonuyla tedavi tamamlanmıştır. Yapmış olduğumuz bu çalışmada ise kırık hattı mesial kökün tamamını içermekte ve fragmanlar birbirinden tamamen ayrılmış olduğundan hemiseksiyon yöntemi uygulanmıştır. Benzer vakalarda çoğu zaman kalan dokunun ağızda bırakılması yerine cerrahi çekimi yapılarak hastalara dental implantlar uygulanmaktadır. Oysaki bu işlemler bazı komplikasyonlara sahip olmasının ${ }^{14}$ yanı sıra pahalıdır ve birçok hasta tarafından karşılanamamaktadır. Ayrıca doku iyileşmesinin beklenilmesi de zaman açısından bir dezavantaj doğurmaktadır.

Fiber postların metal postlara oranla daha esnek olmaları ve dentinle aşağı yukarı aynı elastik modülüne sahip olmaları nedeniyle rezin simanlar ile yapıştırıldıklarında, kuvvetlerin eşit dağılacağı ve daha az kök kırıklarına sebep olacağı düşünülmektedir ${ }^{15}$. Ayrıca, fiber postlar yüzey düzensizliklerinin arttırdığı yüzey alanına bağlanabildiği için minimal preparasyon yapılarak yapıştırma simanları ve kompozit materyallerle uygulanabilmektedirler ${ }^{16,17}$. Bu nedenle kök kanalına fiber post uygulamayı uygun gördük. Üç yıllık takip sonrası klinik ve radyolojik olarak herhangi bir komplikasyon ve patolojiye rastlanılmadı (Resim 7-8).

Sonuç olarak vertikal kök kırığı olan dişlere uygun tedavi seçeneği uygulandığında başarılı sonuçlar alınabilmektedir. Diş çekimlerini takiben dental implant uygulanması hem zaman açısından hem de ekonomik yönden hastalara zorluklar çıkarabilmektedir. Mandibular molar dişlerde meydana gelebilecek kök kırıklarında hemiseksiyon yapılabilmesi bir çok açıdan dental implantlara alternatif bir tedavi yöntemi olarak kullanılabilir.

\section{KAYNAKLAR}

1. Rivera EM, Walton RE. Cracking the cracked tooth code: detection and treatment of various longitudinal tooth fractures. Am Assoc Endodontists Colleagues for Excellence News Lett 2008;2:1-9.

2. Sedgley CM, Messer $\mathrm{HH}$. Are endodontically treated teethmore brittle? J Endod 1992;18:332-5.

3. Parmar G, Vashi P. Hemisection: a case-report and review. Endodontology 2003;15:26-9.

4. Schmitt SM, Brown FH. The hemisected mandibular molar: A strategic abutment. J Prosthet Dent 1987;58:140-5.

5. Fuss Z, Lustig J, Katz A, Tamse A. An evaluation of endodontically treated vertical root fractured teeth: impact of operative procedures. J Endod 2001;27:46-8.

6. Shemesh $H$, van Soest G, Wu M-K, Wesselink PR. Diagnosis of vertical root fractures with optical coherence tomography. J Endod 2008;34:739-42.

7. Patel S, Brady $E$, Wilson $R$, et al. The detection of vertical root fractures in root filled teeth with periapical radiographs and CBCT scans. Int Endod ] 2013;46:1140-52.

8. Özer SY, Ünlü G, Deger Y. Diagnosis and treatment of endodontically treated teeth with vertical root fracture: three cases reports with two-year followup. J Endod 2011;37:97-102.

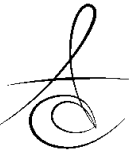


9. Arıkan F, Franco M, Gürkan A. Replantation of vertically fractured maxillary central incisor after repair with adhesive resin. Int Endod J 2008;41:173-9.

10. Öztürk M, Çelik Ünal G. A successful treatment of vertical root fracture: a case report and 4 year follow-up. Dent Traumatol 2008;24:e56-60.

11. Mangold JT, Kern M. Influence of glass-fiber posts on the fracture resistance and failure pattern of endodontically treated premolars with varying substance loss: an in vitro study. J Prosthet Dent 2011;105:387-93.

12. Unver S, Onay EO, Ungor M. Intentional replantation of a vertically fractured tooth repaired with an adhesive resin. Int Endod J 2011;44:106978.

13. Floratos SG, Kratchman SI. Surgical management of vertical root fractures for posterior teeth: report of four cases. J Endod 2012;38:550-5.

14. Misch K, Wang HL. Implant Surgery Complications: Etiology and Treatment. Implant Dentistry 2008; 17: $159-168$.

15. Naumann M, Koelpin M, Beuer F, et al. 10-year survival evaluation for glass fibersupported postendodontic restoration: a prospective observational clinical study. J Endod 2012;38:4325.

16. Franco EB, Lins do Valle A, Pompeia Fraga de Almeida $A L$, et al. Fracture resistance of endodontically treated teeth restored with glass fiber posts of different lengths. J Prosthet Dent 2014;111:30-4.

17. Sarı ME, Külünk T. Ön Diş Kuron Kırıklarının Fiber Post Ve Kompozit Rezin İle Restorasyonu: 3 Olgu Sunumu. Atatürk Üniv Diş Hek Fak Derg 2007; 2:51-4.

\author{
Yazışma Adresi \\ Dr. İbrahim UYSAL \\ Dicle Üniversitesi, \\ Diş Hekimliği Fakültesi, \\ Endodonti Ana Bilim Dalı, 21280, Diyarbakır. \\ Tel: 04122488101 \\ E-mail: ibrahimuysal785@hotmail.com
}

